\title{
ELECTROANALYTICAL ANALYSIS OF GLASSY CARBON ELECTRODE MODIFIED WITH COOH- AND NO ${ }_{2}^{-}$ FUNCTIONALIZED POLYSPYROPHOSPHAZENES
}

\author{
MARIA LUISA VALENZUELA ${ }^{*}$, , REGINA CISTERNAS ${ }^{a}$, PAOLA JARA-ULLOA \\ LISSETTE RODRIGUEZ \\ ${ }^{a}$ Universidad Autónoma de Chile, Instituto de Ciencias Químicas Aplicadas, Centro de Materiales Poliméricos y Macromoléculas,
Av. El Llano Subercaseaux 2801, San Miguel, Santiago, Chile. \\ ${ }^{b}$ Universidad Andres Bello. Facultad de Ciencias Exactas. Departamento de Ciencias Químicas. \\ Av. Republica 275. Santiago, Chile.
}

\begin{abstract}
Glassy carbon electrode modified with $\mathrm{COOH}-$ and $\mathrm{NO}_{2}$-functionalized polyspyrophosphazenes were used to study the redox process of a electroactive probe (ferrocene) in non-aqueous electrolyte. The electrochemical behavior of polyphosphazenes substituted with $\mathrm{COOH}^{2}$ and $\mathrm{NO}_{2}$ groups has been studied using cyclic voltammetry. Their blocking properties depend on the substituent group and on the substitution/nitration degree. The oxoreduction of the couple Fc/Fc ${ }^{+}$occurs with rapid redox kinetic at the modified glassy carbon electrode with high nitration degree $\mathrm{NO}_{2}$-functionalized polyspyrophosphazene. The polymers were immobilized on the glassy carbon surface at different concentrations to study surface charge density effect. In this report were studied the reproducibility, repeatability and stability of the modified electrodes.
\end{abstract}

Keywords: functionalized polyphosphazenes, modified electrode, cyclic voltammetry, blocking effect, ferrocene.

\section{INTRODUCTION}

The polyphosphazenes are a family of inorganic polymers that have backbones consisting of alternating phosphorous and nitrogen atoms [1]. The side groups linked to phosphorus atoms and the ratio in which they are located over the backbone are the main factors determining its physicochemical and chemistry properties. These polymers has been used widely for multiple applications [2]. In earlier works was described the synthesis and characterization of $\mathrm{COOH}-$, as well $\mathrm{NO}_{2}$-functionalized polyspyrophosphazenes (Figure 1) $\left\{\left[\mathrm{NP}\left(\mathrm{O}-\mathrm{C}_{6} \mathrm{H}_{4}-\mathrm{CO}_{2} \mathrm{H}\right)_{2}\right]_{\mathrm{x}}\left[\mathrm{NP}-\left(\mathrm{O}_{2} \mathrm{C}_{12} \mathrm{H}_{8}\right)\right]_{1-\mathrm{x}}\right\}$ $\mathrm{n}(1)$ and $\left\{\mathrm{NP}\left[\mathrm{O}_{2} \mathrm{C}_{12} \mathrm{H}_{8}\left(\mathrm{NO}_{2}\right)_{2}\right]\right\}_{\mathrm{n}}$ (2) respectively, and also were reported its applications. The COOH-functionalized polyphosphazenes $\{[\mathrm{NP}(\mathrm{O}-$ $\left.\left.\left.\mathrm{C}_{6} \mathrm{H}_{4}-\mathrm{CO}_{2} \mathrm{H}\right)_{2}\right]_{\mathrm{x}}\left[\mathrm{NP}-\left(\mathrm{O}_{2} \mathrm{C}_{12} \mathrm{H}_{8}\right)\right]_{1-\mathrm{x}}\right\}_{n}$ (1) [where $\left.\mathrm{x}=0.35,0.5,0.85,1\right]$ have been synthesized by hydrolysis of the corresponding precursors with $[\mathrm{NP}(\mathrm{O}-$ $\left.\left.\mathrm{C}_{6} \mathrm{H}_{4}-\mathrm{CO}_{2} \mathrm{Pr}\right)_{2}\right]$ units. The new polymers have extensive $\mathrm{H}$-bonding between the $\mathrm{COOH}$ groups in the solid state, and those with $\mathrm{x}>0.5$ are very soluble in aqueous $0.5 \mathrm{M}$ sodium carbonate [3]. Recently was reported the synthesis of $\mathrm{NO}_{2}$-functionalized polyspyrophosphazenes, where the regioselective and controlled direct nitration of the homopolymer $\left[\mathrm{NP}\left(\mathrm{O}_{2} \mathrm{C}_{12} \mathrm{H}_{8}\right)\right]_{n}$, [4] was achieved by taking advantage of the unusual high solubility and stability of the precursor in concentrated sulfuric acid, to obtain in one-pot $\left\{\mathrm{NP}\left[\mathrm{O}_{2} \mathrm{C}_{12} \mathrm{H}_{8}\right.\right.$ $\left.\left.\left(\mathrm{NO}_{2}\right)_{\mathrm{x}}\right]\right\}_{\mathrm{n}}$ derivatives (2), with $\mathrm{x}$ between 0.2 and 2 with excellent yields [5]. The $\mathrm{NH}_{2}$-functionalized polyspyrophosphazenes have been prepared by reduction of mono and dinitrated polymers with the Lalancette's reagent and have been proposed as tunable and recyclable supports to immobilize alcohol dehydrogenases and lipases $[6,7]$. The polyphosphazenes are a versatile class of polymers with interesting chemical and physical properties depending on the attached groups in the backbone to produce a spectacular array of materials with diverse properties and applications $[\mathbf{8 , 9}, \mathbf{1 0}, \mathbf{1 1}]$.

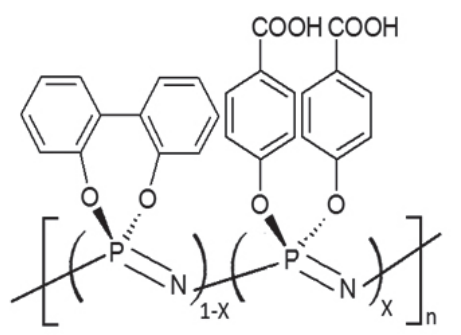

(1)

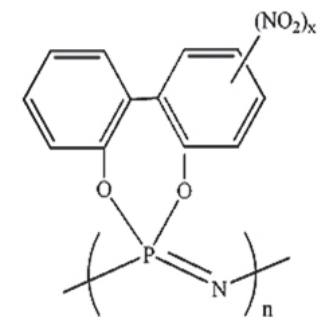

(2)
Figure 1. Copolymers of polyphosphazenes $\left[\mathrm{NP}\left(\mathrm{O}_{2} \mathrm{C}_{12} \mathrm{H}_{8}\right)_{(1-\mathrm{X})}\right]$ $\left[\mathrm{NP}\left(\mathrm{OC}_{6} \mathrm{H}_{4} \mathrm{COOH}\right)_{2}\right]_{\mathrm{X}}(\mathbf{1})$ and $\left\{\left[\mathrm{NP}\left(\mathrm{O}_{2} \mathrm{C}_{12} \mathrm{H}_{8-X}\left(\mathrm{NO}_{2}\right)_{\mathrm{X}}\right\}_{\mathrm{n}}(\mathbf{2})\right.\right.$.
The electrochemical characterization of these kind of compounds have so far little explored. Only the electrochemical behavior of organometallic complexes attached to cyclic and polymeric phosphazenes has been described [12-16]. The focus of this research is to investigate the electrochemical properties of a electrodic surface, as glassy carbon electrode, modified with $\mathrm{COOH}-$ as $\mathrm{NO}$-functionalized polyphosphazenes. A search of "modified glassy carbon electrode" in ScienceDirect came up with more than 25000 references, until 2017. However, reports about electrodes modified with polyphosphazenes have been focused only in order to study its properties as i.e. an amperometric glucose biosensor in several beverages [17]. Recently, we have studied the electrochemical behavior of a glassy carbon electrode modified with polyphosphazenes substituted with $\mathrm{COOH}$ and $\mathrm{NO}_{2}$ groups using cyclic and differential pulse voltammetry in non-aqueous media [results will be published soon]. The results obtained broadly describe the differences between the electrochemical properties of the polymers. We showed that the intensity of the electrochemical response is proportional to the substitution degree in $\mathrm{COOH}-$ as $\mathrm{NO}_{2}$-functionalized polyphosphazenes, which allows to propose an electrochemical via to predict the substituent degree for this kind of polymer only by the measurement of the current intensity.

Therefore, in order to investigate in detail the electrochemical behavior and the barrier properties of the polymers on a electrodic surface and thus to propose interesting and new applications, i.e. electroanalysis, we studied the blocking effect of the glassy carbon electrode modified by either $\mathrm{COOH}-$ or $\mathrm{NO}_{2}$-functionalized polyphosphazenes in non-aqueous media in presence of a electroactive probe redox couple.

\section{EXPERIMENTAL}

All chemicals employed in this work were of analytical-reagent grade: tetrabutylammonium perchlorate (TBAP) Fluka, N, N-dimethylformamide (DMF) JT Baker; dimethyl sulfoxide (DMSO) Aldrich; ferrocene 98\%, Aldrich. Extra pure nitrogen gas, Indura.

The synthesis of $\mathrm{COOH}-$ and $\mathrm{NO}_{2}$-functionalized polyphosphazenes was realized following the procedure previously reported $[3,4,5]$ and the $x$ values are described in Table 1.

Working solutions of polymers were obtained by diluting the corresponding $0.02 \mathrm{M}$ standard stock solutions. The working solutions were obtained by diluting in a $10 \mathrm{~mL}$ flask an aliquot of stock solution to a concentration of $1 \mathrm{mM}$. The flask was diluted to volume with the solvent used for the stock solution. 
Table 1. Degrees of functionalization $\mathrm{x}$ and nomenclature.

\begin{tabular}{|c|c|c|c|c|}
\hline \multicolumn{2}{|c|}{$\begin{array}{c}\text { COOH- functionalized } \\
\text { polyphosphazene }\end{array}$} & \multicolumn{2}{|c|}{$\mathrm{NO}_{2}-$ functionalized polyphosphazene } \\
\cline { 1 - 4 } $\mathrm{x}^{l}$ & Polymer & $\mathrm{x}^{2}$ & Polymer & \\
\hline 0.35 & $1 \mathrm{a}$ & 0.25 & $2 \mathrm{a}$ & \multirow{2}{*}{ mononitro } \\
\hline 0.50 & $1 \mathrm{~b}$ & 0.5 & $2 \mathrm{~b}$ & \multirow{2}{*}{ dinitro } \\
\hline 0.85 & $1 \mathrm{c}$ & 1 & $2 \mathrm{c}$ & \\
\hline 1.0 & $1 \mathrm{~d}$ & 1.5 & $2 \mathrm{~d}$ & \multirow{2}{*}{} \\
\hline & & 2.0 & $2 \mathrm{e}$ & \\
\hline
\end{tabular}

${ }^{I}$ substitution degree, ${ }^{2}$ nitration degree

Voltammetric experiments were performed with CHI 620D workstation (CH Instruments Inc., USA) attached to a PC with the appropriate software for total control of the experiments and data acquisition and treatment. A conventional three-electrode cell was used, a 3-mm diameter glassy carbon electrode (GCE) (model CHI104, CH Instruments) was used as working electrode. $0.8 \mathrm{~mm}$ diameter $\mathrm{Pt}$ wire and $\mathrm{Ag}|\mathrm{AgCl}| \mathrm{KCl}$ (sat.) electrodes (mode $\mathrm{CHI111,} \mathrm{CH}$ Instruments) were used as counter and reference electrodes, respectively. The working electrode was mechanically polished, rinsed, washed in an ultrasonic bath for 10 minutes and washed with DMF before each measurement. The immobilization of the polymer solutions was performed by casting the GCE with $5 \mu \mathrm{L}$ of the polymer dispersion. All the voltammetric and open-circuit potential experiments were obtained after bubbling with $\mathrm{N}_{2}$ for 10 min in the cell before each experiment. The temperature was kept constant at $25 \pm 0.1{ }^{\circ} \mathrm{C}$ in all experiments.

\section{RESULTS AND DISCUSSION}

1. Electrochemical study of a modified GCE with $\mathrm{COOH}-$ and NO-functionalized polyphosphazenes

In order to study the effect of a $\mathrm{COOH}-$ and $\mathrm{NO}_{2}$-functionalized polyphosphazenes film at the surface of a glassy carbon electrode were investigated their electrochemical responses in presence of a electroactive redox specie. The characterization of the glassy carbon electrode after the modification with polymers $1 \mathrm{a}-1 \mathrm{~d}$ and $2 \mathrm{a}-2 \mathrm{e}$ were performed using ferrocene redox probe in non-aqueous media.

Figure 2a. and its insert show clearly that the electrochemical reaction of ferrocene is suppressed when a glassy carbon electrode modified with $\mathrm{COOH}-$ functionalized polyspyrophophazene with different substitution degrees is used. Ferrocene/ferrocenium $\left(\mathrm{Fc} / \mathrm{Fc}^{+}\right)$couple do not show electrochemical activity on the modified electrode. In this case, the characteristic oxidation reduction signals of the redox couple are not detected comparing with a glassy carbon electrode without modification. The electrochemical response (anodic and cathodic current intensities) of $\mathrm{Fc} / \mathrm{Fc}^{+}$couple decrease depending on the degree of substitution $x$. The higher substituted polymer does not allow the electron transfer.
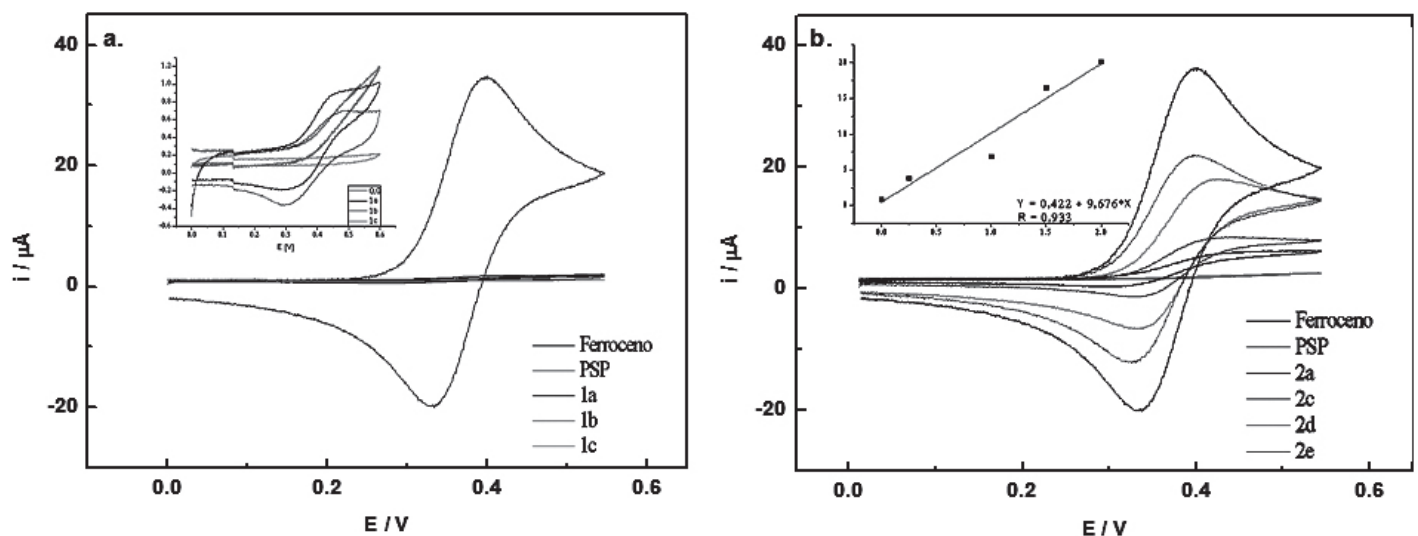

Figure 2. Cyclic voltammograms of ferrocene $1 \mathrm{mM}$ on GCE and on GCE modified with a. COOH-functionalized polyspyrophosphazenes, insert: signals of GCE modified and b. $\mathrm{NO}_{2}$-functionalized polyphosphazenes, insert: nitration degree vs. current $(\mu \mathrm{A})$. In DMF + 0.1 M TBA, with DMSO as dispersing agent. Scan rate $0.1 \mathrm{~V} \mathrm{~s}^{-1}$.

The Figure 2b. show the characterization of GCE before and after the modification with polymers $2 \mathrm{a}-2 \mathrm{e}$ using by the ferrocene redox probe in non-aqueous media. In the figure is possible to observe that a increase in the nitration degree in the polymer chain gives to the modified electrode non-insulated characteristics. The insert shows a linear relation between the nitration degree and the current. The electrochemical response (anodic and cathodic current intensities) of $\mathrm{Fc} / \mathrm{Fc}^{+}$couple increases depending on the nitration degree. Oxidation-reduction of the couple $\mathrm{Fc} / \mathrm{Fc}+$ occurs with rapid redox kinetic at the modified glassy carbon electrode with $\mathrm{NO}_{2}$-functionalized polyspyrophosphazene.

The differences between both types of polymers under the same conditions, could be attributed to the structural differences and the effect of the charge of $\mathrm{Fc}^{+}$ion and its interaction with $\mathrm{COOH}$ and $\mathrm{NO}_{2}$ groups present in the polymer. In this respect, C. Saby et. al. [18] have reported the effect of a 4-carboxyphenyl or a 4-nitrophenyl thin film at the surface of a glassy carbon electrode on their electrochemical responses in the presence of various electroactive probes. The blocking effect of the films depend primarily on electrostatic and electrolyte/ solvent effects. Both $\mathrm{COOH}$ and $\mathrm{NO}_{2}$ groups show that the electrochemica reaction of ferrocene is completely blocked, contrary to polyphosphazenes films behavior.

The behavior of $\mathrm{NO}_{2}$-functionalized polyspyrophosphazene with the higher nitration degree which present the best results for of $\mathrm{Fc} / \mathrm{Fc}^{+}$couple electrochemical response can be found below.
2. Effect of the concentration of NO-functionalized polyspyrophosphazene (2e) dispersed on glassy carbon electrode

A surface charge density might affect the electrochemical behavior of modified electrodes for this reason, a study of concentration of the polymers onto glassy carbon was performed. These concentration studies allow the determination of the amount of polymer which a dispersion can be prepared to get a good ferrocene $\mathrm{Fc} / \mathrm{Fc}^{+}$signal with the modified electrode. These measurements were performed by modifying the five electrodes with polymer 2e (higher nitration degree) at dispersion concentrations between 2 and $10 \mathrm{~g} / \mathrm{l}$ (Figure 3).

Even though the functionalized $\mathrm{NO}_{2}-$ functionalized polyspyrophosphazenes conferred non-insulated characteristic to the modified electrode compared to $\mathrm{COOH}$-functionalized polyspyrophosphazenes these polymers do not reach the glassy carbon electrode signals without modification. The optimal concentration dispersions are in the range of 4 to $8 \mathrm{~g} / \mathrm{l}$, which have higher anodic signal $i_{p, a^{*}}$ The observed phenomenon can be explained because the range of the dispersion has a greater amount of polymer physically absorbed, which covers a larger surface of the electrode. The best example is the dispersion concentration $4 \mathrm{mg} / \mathrm{mL}$, the values of the current intensity are low and its coefficient of variation is within the acceptable range $(\% \mathrm{CV}<$ $10 \%)$ [19-21]. 


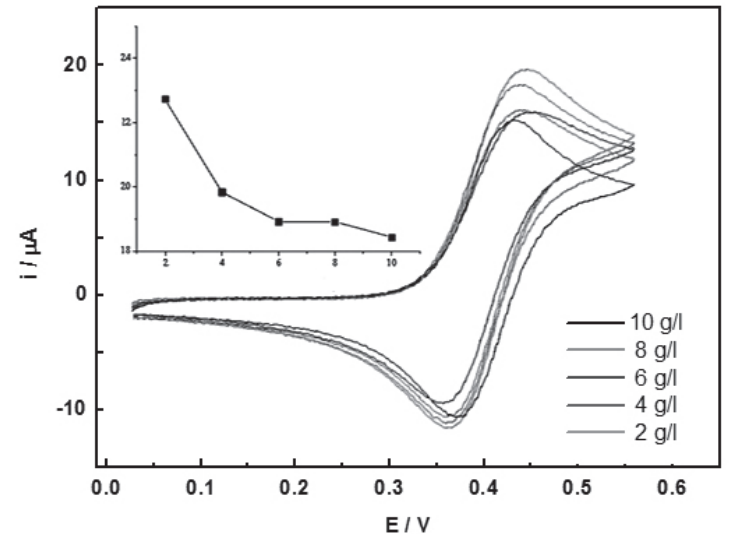

Figure 3. Cyclic voltammogram of ferrocene $1 \mathrm{mM}, 0.1 \mathrm{M}$ in acetonitrile TBA on glassy carbon electrode modified with polymer (2e) at different concentrations, with DMSO as a dispersing agent.

Table 2. Summary of voltage and current ferrocene signals, measured with electrodes modified with polymer (2e) as a dispersing agent in DMSO at different concentrations.

\begin{tabular}{|c|c|c|c|}
\hline $\begin{array}{c}\text { Concentration/ } \\
\mathrm{g} \mathrm{l}^{-1}\end{array}$ & $\mathrm{E} / \mathrm{V}$ & $\mathrm{i}_{\mathrm{p}, \mathrm{a}} / \mu \mathrm{A}$ & $\% \mathrm{CV}$ \\
\hline 10 & $0.461 \pm 0.003$ & $18.423 \pm 2.526$ & 13.71 \\
\hline 8 & $0.468 \pm 0.007$ & $18.908 \pm 1.726$ & 9.13 \\
\hline 6 & $0.466 \pm 0.005$ & $18.916 \pm 2.224$ & 11.75 \\
\hline 4 & $0.465 \pm 0.006$ & $19.837 \pm 1.596$ & 8.05 \\
\hline 2 & $0.469 \pm 0.002$ & $22.729 \pm 3.352$ & 14.75 \\
\hline
\end{tabular}

Once the electrodes modified with polymers were characterized, the next studies provided more information about the quality of the modification in terms of reproducibility, repeatability and stability of the polymer in solution over time.

3. Reproducibility, repeatability and stability of GCE modified with $\mathrm{NO}_{2}$-functionalized polyspyrophosphazenes

The reproducibility and repeatability of the GCE modified with $\mathrm{NO}_{2}-$

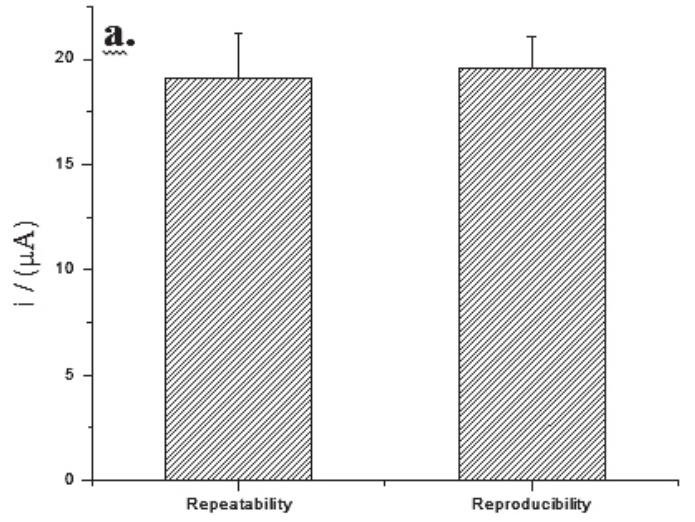

Figure 4. a. Reproducibility, repeatability of GCE modified with $\mathrm{NO}_{2}$-functionalized polyspyrophosphazene and b. dispersion stability after 11 weeks.

\section{CONCLUSIONS}

The studies performed by cyclic voltammetry in the modified electrode of polyphosphazenes functionalized with $\mathrm{COOH}$ and $\mathrm{NO}_{2}$ groups, broadly described the differences between the electrochemical properties of these substituents.

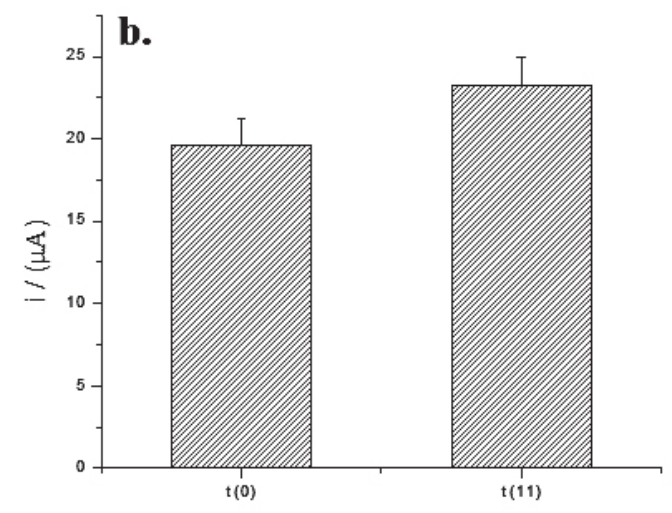
and, under the same conditions, the polymers functionalized with $\mathrm{NO}_{2}$ groups conferred non insulating properties. polyspyrophosphazenes electrode but not at $\mathrm{GCE} / \mathrm{COOH}$-functionalized functionalized polyspyrophosphazenes (2a-2e) were examined . Six electrodes were fabricated based on the same construction type and measured in the same solution. Under these conditions were evaluated the changes of the anodic peak current of the $\mathrm{Fc} / \mathrm{Fc}^{+}$signal. To determine the accuracy of these results was calculated their coefficient of variation (CV) considering as acceptable value a $\% \mathrm{CV}<10 \%[19-21]$. As seen in Table 3 the CVs for polymers with higher nitration degree (mononitro $2 \mathrm{c}$ and dinitro $2 \mathrm{e}$ ) are lower comparing with polymer 2 a (lowest nitration degree) and remain within an acceptable range $(\% \mathrm{CV}<10 \%)$. The modification of GCE with polymers $2 \mathrm{c}$ and $2 \mathrm{e}$ had good reproducibility.

Table 3. Summary data of anodic current signals of Fc, measured with electrodes modified with polymers 2 in DMSO as dispersant.

\begin{tabular}{|c|c|c|}
\hline Polymer & $i_{p, a} / \mu \mathrm{A}^{*}$ & $\% \mathrm{CV}$ \\
\hline $2 \mathrm{a}$ & $3.776 \pm 1.085$ & 28.73 \\
\hline $2 \mathrm{c}$ & $6.858 \pm 0.333$ & 4.860 \\
\hline $2 \mathrm{~d}$ & $16.477 \pm 1.907$ & 11.58 \\
\hline $2 \mathrm{e}$ & $19.329 \pm 1.453$ & 7.520 \\
\hline
\end{tabular}

* Average data

The repeatability of one GCE modified with $\mathrm{NO}_{2}$-functionalized polyspyrophosphazene (2e, $4 \mathrm{~g} / \mathrm{L}$ dispersed) was also studied by measuring de voltammetric response of $\mathrm{Fc} / \mathrm{Fc}^{+}$couple by eight successive runs in the same solution of ferrocene. The results for this test are: average anodic current intensity $=19.443 \mu \mathrm{A}$ and $\% \mathrm{CV}=11.47 \%$. Figure 4 a show that the results of repeatability of the method are acceptable and show that the modified electrode was stable.

Additionally, studies with respect to the temporal stability of the dispersion were conducted with electrodes modified with polymer $2 \mathrm{e}$ as well. For the first voltammogram the parameters were measured and recorded initially at point $\mathrm{t}=0$, while for the second were used the same dispersions, which had been storing away from light and at room temperature until the day of the test $(t=11$ weeks, see Figure $4 . b)$. Six measurements were performed similarly, with different electrodes. The ferrocene redox signal observed in both graphs is the same. The peak currents after 11 weeks storing increase in a $21 \%$ of their original values. This increase could be attributed to the oxidation of the electrode at atmospheric conditions. groups gave to the modified glassy carbon electrode insulation characteristics

A rapid redox kinetic of the $\mathrm{Fc} / \mathrm{Fc}^{+}$system at $\mathrm{GCE} / \mathrm{NO}_{2}$-functionalized 
polyspyrophosphazenes is reported. This behavior is attributed to structural differences and charge of $\mathrm{Fc}^{+}$ion. As the surface charge density affect the electrochemical behavior of modified electrodes, the study of the concentration of dispersed polymer show that a optimal dispersion concentration is 4 $\mathrm{g} / 1(\% \mathrm{CV}<10 \%)$. The electrochemical response of the electrodes were reproducible, repeatable but not stable over the time.

\section{ACKNOWLEDGEMENTS}

The financial support of Fondecyt under Projects 1130416 and 1130505.

\section{REFERENCES}

1.- M. A. Olshavsky, H. R. Allcock, Macromolecules 30, 4179, (1997)

2.- M. Gleria, R. De Jaeger, Top. Curr. Chem. 250, 165, (2005)

3.- G. A. Carriedo, F. J. Garcia Alonso, C. Diaz, M. L. Valenzuela, Macromolecules 38 3255, (2005)

4.- G. A. Carriedo, F. J. Garciia Alonso, P. Gomez- Elipe, J. I. Fidalgo, J. L. Garcia-Alvarez, A. Presa Soto, Chemical European Journal 9, 3833, (2003)

5.- G. A. Carriedo, A. Presa-Soto, M. L. Valenzuela, Macromolecules 41 6972, (2008)

6.- A. Cuetos A., M. L. Valenzuela, I. Lavandera, V. Gotor, G. A. Carriedo, Biomacromolecules 11, 1291, (2010)

7.- A. Cuetos, A. Rioz-Martinez, M. L. Valenzuela, I. Lavandera, G. de Gonzalo, G. A. Carriedo, V. Gotor, J Mol Catal B: Enzym 74, 178, (2012)
8.- S. Rothemund, I. Teasdale, Chem. Soc. Rev. (2016) DOI: 10.1039/ C6CS00340K

9.- A.J. Polberio, M. F. Guedes da Silva, Synthesis and Characterization of Poly(organophosphazenes); In M. Geleria, R. DeJager eds. New York: Nova Science, 2004; Chapter 14, p. 343

10.- D. H. Shim, H. J. Ko, G. Volker, A. A. Potter, G. Mutwiri, A. Babiuk, N. Kweon, Vaccine 28, 2311, (2010)

11.- S. Sethuraman, L. S. Nair, S. El-Amin, M. T. Nguyen, A. Singh, N. Krogman, Y. E. Greish, H. R. Allcock, P. W. Brown, C. T. Laurencin, Acta Biomater 6, 1931, (2010)

12.- G. A. Carriedo, L. Fernández-Catuxo, F. J. García-Alonso, P. GómezElipe, J Organometallic Chem 503, 59, (1995)

13.- C. Diaz, M. L. Valenzuela, Polyhedron 21, 909, (2002)

14.- G. A. Carriedo, F. J. Garcia-Alonso, P. Gomez -Elipe, C. Diaz, N Yutronic, J Chilean Chem Soc 48, 25, (2003)

15.- C. Diaz, M. L. Valenzuela, M. Barboza, Material Research Bulletin 39, 9, (2004)

16.- C. W. Allen, (2014) DOI: 10.1080/10426507.2014.983595

17.- D. Ucan, F. E. Kanik, Y. Karatas, L. Toppare, Sensor Actuat. B 201, 545, (2014)

18.- C. Saby, B. Ortiz, G. Y. Champagne, D. Bélanger, Langmuir 13, 6805, (1997)

19.- D. T. Bowman, J. Cotton Sci. 5, 137, (2001)

20.- J. K. Patel, N. M. Patel, R. L. Shiyani, Curr. Sci. 81, 9, 1163, (2001)

21.- D. Ruíz, A.M. Sánchez.. Apuntes de estadística. (2006) www.eumed.net/ libros-gratis/2006a/rmss/index.htm. 